San Jose State University

SJSU ScholarWorks

Master's Theses

Master's Theses and Graduate Research

1990

\title{
A comparison of two methods of teaching geometry at the middle level as influenced by the Van Hiele Model
}

Mary Elizabeth Kipfinger

San Jose State University

Follow this and additional works at: https://scholarworks.sjsu.edu/etd_theses

\section{Recommended Citation}

Kipfinger, Mary Elizabeth, "A comparison of two methods of teaching geometry at the middle level as influenced by the Van Hiele Model" (1990). Master's Theses. 3274.

DOI: https://doi.org/10.31979/etd.hy2q-6tr9

https://scholarworks.sjsu.edu/etd_theses/3274

This Thesis is brought to you for free and open access by the Master's Theses and Graduate Research at SJSU ScholarWorks. It has been accepted for inclusion in Master's Theses by an authorized administrator of SJSU ScholarWorks. For more information, please contact scholarworks@sjsu.edu. 


\section{INFORMATION TO USERS}

The most advanced technology has been used to photograph and reproduce ti:is naniscript from the microfilm master. UMI films the text directly from the original or copy submitted. Thus, some thesis and dissertation copies are in typewriter face, while others may be from any type of computer printer.

The quality of this reproduction is dependent upon the quality of the copy submitted. Broken or indistinct print, colored or poor quality illustrations and photographs, print bleedthrough, substandard margins, and improper alignment can adversely affect reproduction.

In the unlikely event that the atthor did not send UMI a complete manuscript and there are missing pages, these will be noted. Also, if unauthorized copyright inaterial had to be removed, a note will indicate the deletion.

Oversize materials (e.g., maps, drawings, charts) are reproduced by sectioning the original, beginning at the upper left-hand corner and continuing from left to right in equal sections with small overlaps. Each original is also photographed in cne exposure and is included in reduced form at the back of the book.

Photographs included in the original manuscript have been reproduced xerographically in this copy. Higher quality $6 " \times$ " 9 " black and white photographic prints are available for any photographs or illustrations appearing in this copy for an additional charge. Contact UMI directly to order:

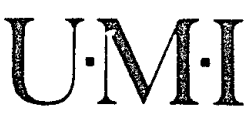

Universily Microfilms International

A Bell \& Howel! Intormalion Company 


\section{.}


Order Number 1340527

A comparison of two methods of teaching geomitry at the middle school level as influenced by the Van Hiele model

Kipfinger, Mary Elizabeth, M.A.

San Jose State University, 1990 
- $\cdots$ 
A COMPARISON OF TWO METHODS

OF TEACHING GEOMETRY AT THE MIDDLE SCHOOL LEVEL

AS INFLUENCED BY THE VAN HIELE MODEL

\author{
A Thesis \\ Presented to \\ The Faculty of the School of Education \\ San Jose State University
}

\author{
In Partial Fulfillment \\ of the Requirements for the Degree \\ Master of Arts
}

By

Mary Elizabeth Kipfinger

May, 1990 
APPROVED FOR THE DEPARTMENT OF EDUCATION

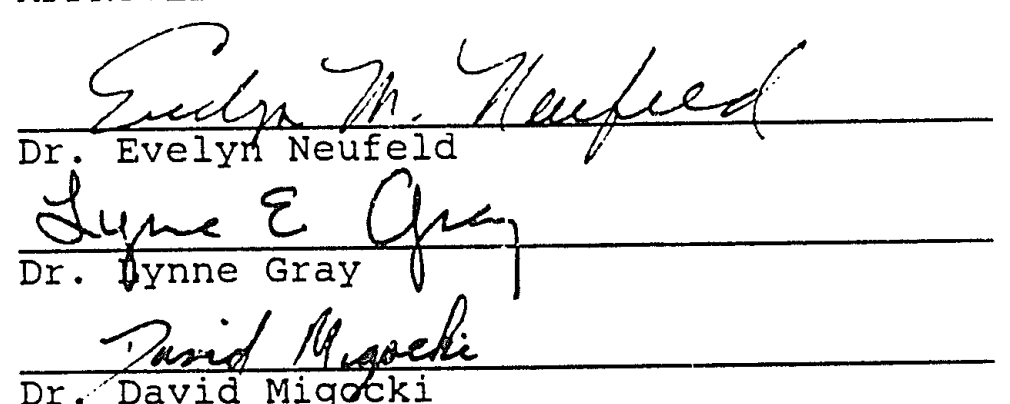
Dr. David Migocki

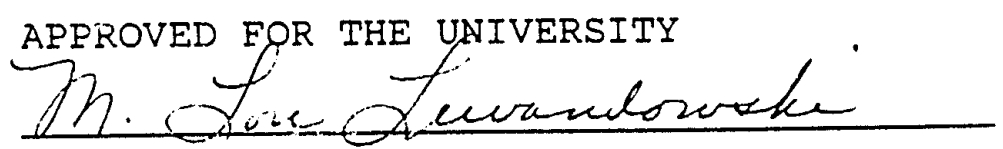




\section{ABSTRACT}

A COMPARISON OF TWO METHODS

OF TEACHING GEOMETRY AT THE MIDDLE SCHOOL LEVEL AS INFLUENCED B'Y THE VAN HIELE MODEL

By Mary Elizabeth Kipfinger

This research project concerns middle school students' achievement in geometry. Current research supports the hypothesis that students of this age are not conceptually ready to deal with abstract geometric formulas, having had little or no concrete, hands-on, experiences with geometric concepts. The textbook, by itself, has been shown to be less effective than a method which uses various manipulative materials when teaching geometry.

This study compared the textbook method with the manipulative method, using a control and experimental group. Sixth grade advanced math students were selected for the seven week project. After an initial pretest, treatment for the control group consisted of the textbook method, whereas the experimental group was treated using the manipulative method.

A comparison of pretest means found no significant differences between the experimental and control groups. After treatment, statistically significant differences were found in geometry posttest scores in favor of the manipulative rnethod. 


\section{ACKNOWLEDGEMENTS}

I dedicate this paper to my mother, whose persistence and constant support made this paper a reality.

I also gratefully acknowledge Dr. Neufeld, who went the extra mile to insure that this paper would be something of which to be proud.

I especially thank my daughters, Beth and April, who were always patient and thoughtful. 


\section{TABLE OF CONTENTS}

ACKNOWLEDGEMENTS

CHAPTER

I. INTRODUCTION 1

Problem statement $\quad 6$

Purpose $\quad 7$

Hypothesis $\quad 8$

Operational Definitions 8

II. REVIEW OF THE LITERATURE 9

Introduction 9

Cognitive Development 9

Manipulatives 14

The Teacher 16

State and National Recommendations 18

Summary 20

III. METHODOLOGY 22

Research Universe and Sampling Procedure 22

Limitations $\quad 2.3$

Delimitations 23

Timetable and Method of Delivering
Material

Data-Gathering Tools/Instruments 28

Procedures For Collection of Data 28

Procedures For Analysis of Data 28 
IV. RESULTS 29

V. CONCLUSION 34

summary $\quad 34$

Discussion $\quad 35$

Recommendations $\quad 36$

$\begin{array}{ll}\text { REFERENCES } & 37\end{array}$ 


\section{CHAPTER I - INTRODUCTION}

Geometry is the study of space and spatial relationships. It is all around us. The child experiences it as he observes, handles, and alters; the architect experiences it when he contemplates and designs a building; the carpenter experiences it when he designs and constructs a cabinet; and the botanist experiences it as he examines and studies the shapes and patterns found in plant life. In a very real sense, one experiences physical geometry, and this experience is extreme. $Y$ important. (O'Daffer and Clemens, 1977, p. 8)

Early man used geometric concepts to solve everyday problems. He reduced the shape of nature to simpler forms which were used in a multitude of ways. Arrowheads, baskeis, and pottery demonstrated an intuitive knowledge of geometry (O'Daffer and Clemens, 1977). Geometry was utilized to build huts, to erect tents and excavate caves (Pedoe, 1983).

As time went on, man's knowledge of geometry became more sophisticated. The Egyptians used geometric techniques to re-mark the land that was annually washed away by the Nile River. Thus the word "geometry" meaning "earth measure" originated. Later, Euclid and other Greeks aided the evolution of geometry from the purely physical level to the more abstract, theoretical level (O'Daffer and Clemens, $1977)$.

Euclid, a great matherlatician, born in the third century B.C., wrote what is perhaps the most influential book on mathematics. That book, Elements of Geometry, first printed in modern form in 1482 , survived through the middle 
ages and is considered to be the first book on mathematics of any importance (Pedoe, 1983). Euclid's book is the oldest geometry test still in use and many modern day textbooks contain Euclid's writings (American Educator Encyclopedia, 1976).

Beginning with certain fundamental propositions, or axioms, Euclid provides a step-by-step description of relationships among geometric figures and how these relationships can be proven. A sequence of postulates and axioms is called a proof (American Educator Encyclopedia, 1976). A proof can be defined as "the process of reasoning from a set of premises through a series of connected inferences to a conclusion, in such a way that any doubt about the conclusion must be referred back to the premises, rather than to the logical necessity of the inferences" (Driscoll, 1988, p. 155). The teaching of geometry has been so influenced by Euclid's work that most secondary students have thought of "proofs" and "geometry" as synonymous (O'Daffer and Clemens, 1977).

The traditional textbook method of teaching geometry, at the middle school level, consists of one unit of formal proofs, contained within a seneral mathematics text, and taught for a very limited amount of time, (approximately one month) (Shaughnessy and Burger, 1985). The textbook method depends heavily on rote-memorization along with worksheets and homework exercises (Suydam, 1985). 
The non-traditional manipulative method, recommended by the National Council of Teachers of Mathematics (1989) in the Curriculum and Evaluation Standards for School Mathematics and in the Mathematics Framework for California Public Schools Kindergarten Through Grade Twelve (1985), consists of a less formal geometry approach emphasizing the direct use of manipulative materials to study geometric shapes and their translations, reflections, and rotations ( Suydam, 1985).

According to $\operatorname{Cox}(1985)$, geometric concepts are often neglected in elementary and middle schools in favor of teaching computational skills. When students progress to high school they are expected to write proofs about geometric concepts with which they have had little experience and which for the most part they do not understand.

Perhaps one of the best known theorists of cognitive development is Jean Piaget. Piaget, a Swiss genetic epistemologist, created, through over firizy years of intensive research, a developmental theory. According to Piaget, "mental development is a continuous construction comparable to the erection of a vast building that becomes more solid with each addition" (Piaget, 1968, p. 4). If material is presented above the cognitive level of the student, learning cannot take place (Prevost, 1985). It is like putting the roof on a building before the walls are 
erected. Textbooks, regardless of how they are used, are usually written at a level beyond the capabilities of midale school students (Shaughnessy and Burger, 1985).

Following Piaget, Pierre and Dina van Hiele, two Dutch educators, developed a theory dealing with the match between students' cognitive levels and their readiness to understand geometric concepts. The van Hieles' research, which had its roots in Piaget's work, focused primarily on five levels of geometric conceptualization. The five levels are visualization, analysis, informal deduction, formal deduction, and rigor (Shaugnessy and Burger, 1985). The van Hieles asserted that higher levels of thinking are rarely reached by most students because geometry materials are improperly sequenced (Fuys, Geddes, and Tischler, 1988).

An example of the influence Piaget and the van Hieles have had on the teaching of geometry can be seen in the Soviet Union. A radical change has taken place in the Soviet geometry curriculum (Fuys, Geddes, and Tischler, 1988). Informal geometry is now emphasized in the early and middle grades, with manipulatives replacing the traditional Euclidean focus on proofs (Driscoll, 1988).

After analyzing the van Hiele theory, Fuys, Geddes, and Tischler suggested six teaching strategies (Levels 0 through 5). Three of the six mention the use of manipulatives as vital to the teaching of geometry. The strategies are as follows: 
(a) Do not rely on a text to fill in the levels. Use texts as a follow-up to more exploratory activities in geometry.

(b) Encourage students to talk about geometric concepts, and to develop expressive language. That is, ask them to describe a figure, rather than just to select a name for it from a list.

(c) To help students fill in level 0 understanding of geometric concepts, the teacher should be alert to possible misconceptions formed as a result of limited visual examples. Textbook presentations can be supplemented by many manipulative models and examples in the environment.

(d) To help students progress to level 1 thought, the teacher can supplement the one or few examples in the text development of a property by encouraging students to test many examples, with drawings or manipulatives, to determine if properties are true or false.

(e) To help students progress to level 2 thought, the teacher can raise the level required in many routine exercises by asking "Why?", or "Explain your answer."

(f) The teacher can revise or supplement tests to reflect higher levels of thinking (1988, p. 178).

Fuys, Geddes, and Tischler stated further that teachers should be knowledgeable about the way children learn, and that an awareness of the van Hiele levels would inspire teacheis to use manipulative materials in the classroom (Fuys, Geddes, ani Tischler, 1988).

Manipulative materials are objects which can be used to represent mathematical concepts. They can be touched, rearranged and moved about. These objects can be devices which are utilized daily, such as measuring instruments or rulers, or they may be specifically designed materials to 
aid in the instruction of mathematical concepts, such as blocks or geoboaras (Kennedy, 1986). According to Driscoll, Manipulatives not only show the way to conceptual understanding, but they provide experiences in which children can transfer their understanding smoothly from one concept to another" (1988, p. 27).

According to the Mathematics Framework for California Public Schools Kindergarten Through Grade Twelve (1985), manipulative materials should be used to introduce concepts for the purpose of progressing to an abstract representation of the concept being taught. Furthermore, it is advocated that manipulative materials be used even at the high school level.

On a national level, the Curriculum and Evaluation Standards for School Mathematics (1988, p. 24) states that, "Calculators, computers, courseware, and manipulative materials are necessary for good mathematics instruction; the teacher can no longer rely solely on a chalkboard, chalk, paper, pencils, and a text."

problem statement

According to the van Hiele research, many secondary students experience difficulties in high school geometry that stem from a lack of understanding that began in the early and middle grades (Fuys, Geddes, and Tischler, 1988). Furthermore, only about fifty percent of high school students now choose to enroll in geometry courses and more 
than fifty percent state that the topic is unimportant (Driscoll, 1988).

The van Hieles have concentrated their research on the difficulties students were having in geometry. They believe that geometry, at all grade levels, involves a relatively high level of thinking and that most students do not attain these levels before they are required to reason abstractly about geometric concepts. The van Hieles found textbooks to be structured in such a way that many students could not grasp the required concepts (Fuys, Geddes, and Tischler, 1988). Kennedy suggests that the use of manipulative materials be emphasized in the classroom to facilitate the transition from concrete to abstract thought (1986) and that geometry, at the middle school level, should emphasize the recognition of basic geometric figures before going on to more abstract processes, such as analysis and ordering, two of the more common activities at this level (Prevost, $1985)$

Purpose

Builring on the van Hieles' suggestions, the purpose of this research was to study the effects of using concrete materials on students' successes in geometry by comparing two methods of teaching geometry at the sixth grade level. one group was taught using the manipulative method, while the other was taught using the textbook method. Pre- and 
posttests were administered to measure progress in concept development that could be related to the van Hiele levels. Hypothesis

There will be a significant difference in posttest geometry achievement scores in favor of those students taught using the manipulative method rather than those taught using the textbook method.

Operational Definitions

The following terms are used throughout this report and are defined here to establish clear and concise meaning:

Manipulatives - Concrete materials, e.g., tangrams, geoboards, and Pattern Blocks.

Tangrams - A set of seven shapes consisting of two large triangles, two small triangles, one medium triangle, a parallelogram, and a square.

Geoboards - A matrix of nails placed approximately one inch apart on a square board. Rubberbands are used to create geometric shapes.

Logo - A programming language that allows exploration of geometric concepts by moving a "turtle" around the screen.

Dot paper - Papes rith a matrix of dots placed approximately one centimeter apart.

Pattern Elocks - Geometric blocks used to familiarize students with the properties of shapes.

Tesselations - A pattern of shapes which cover a plane with no gaps or overlaps. 
CHAPTER II - REVIEW OF THE LITERATURE

\section{Introduction}

Geometric concepts are often neglected in elementary and middle school, overshadowed by computational skills and heavy use of the textbook (Cox, 1985). Students progress to high school and are expected to write proofs about geometric concepts they do not undersiand. As a result, many high school students are not inrolling in geometry courses because either the topic seems unimportant to them or they feel that the subject is too difficult (Driscoll, 1988). According to the van Hiele research, it was found that the cognitive level of most students is below the necessary abstract level required to understand the concepts encountered in high school geometry textbooks (Fuys, Geddes, and Tischler, 1988). The purpose of this study was to compare two methods of teaching geometry, the traditional textbook method and the manipulative method.

\section{Cognitive Development}

Piaget spent many years investigating cognitive development. According to Piaget, a majority of students at the middle school level are beginning to enter the stage of formal operational thought. They are, however, incapable of consistent and stable abstract thought. Students are considered to be thinking at the formal operational level when they "can internalize thought, think about thinking, keep two variables in mind at one time, and see a concept as 
part of a larger system" (Driscoll, 1988, p. 15-16). Prior to formal operational thought, students are in the concrete operational stage where, although they can classify and order objects according to quantity, size, and set inclusion, they cannot think abstractly (Piaget, 1968).

The proofs found in the geometry curriculum are complex cognitive tasks. Many deductive paths must be weighed while constructing proofs. Pre-formal thinkers, however, are not ready to understand the meaning or role of an axiomatic system (Shaughnessy and Burger, 1985). The steps of the proof are taxing for them (Driscoll, 1988). Unfortunately, the geometry curriculum, even at the secondary level, contains many proofs for which the students are not yet developmentally ready (Driscoll, 1988).

Influenced by Piaget's research, Dutch educators Pierre van Hiele and his wife, Dina van Hiele-Geldof, conducted a three year study on how children learn geometry. They were attempting to explain why many students have trouble with higher order cognitive processes, such as proofs (Suydam, 1985).

The van Hieles began their research when it became obvious that students were not experiencing success in geometry. They found that the level of thought required to master the concepts was beyond the students' capabilities. It was surmised that students had not had sufficient experiences in thinking at lower levels (Fuys, Geddes, and 
Tischler, 1988). Their research found that the developmental levels by which children learn geometry correspond with Piagetian theory (Fuys, Geddes, and Tischler, 1988). The research focused not only on levels of thought but also on helping students make the transition from one level to the next (Fuys, Geddes, and Tischler, 1988).

The levels the van Hieles developed are as follows: Level 0 - Visualization. Students see the geometric figure as a whole. They can identify, compare, name and classify objects according to the appearance of the geometric shape. Level 1 - Analysis. Figures are analyzed in terms of their components. Students can analyze relationships among components and can discover rules or properties of a class of shapes by manipulations. Students at this level do not see how one figure relates to another.

Level 2 - Informal Deduction. Simple inferences can be made by interrelating previously discovered rules or properties by informal arguments. Level 3 - Formal Deduction. Theorems involving axioms and undefined terms can be deduced. Students can establish interrelationships among theorem networks. The construction of original proofs occurs at this level. Level 4 - Rigor. Theorems can be established in different postulational systems. Theorems can be analyzed and compared in these postulational systems (Fuys, Geddes, and Tischler, 1988). 
In a study conducted by Usiskin, many tenth grade students failed to demonstrate even the level one skills, indicating that students had not been adequately prepared at the lower grades for higher levels of thinking (Usiskin, 1982). His study also suggested that there was only a fifty percent chance of success in a geometry course that emphasized proofs if level three had not been attained (Usiskin, 1982). Many courses approach geometry at level three.

Usiskin suggested eliminating some of the geometry curriculum, providing students the extra time needed to acquire the necessary geometry skills. His suggested eliminations are as follows:

1. The obvious statements which require vigorous proofs involving points, lines, and angles. These obvious facts should only be covered informally.

2. The laborious method by which proofs are written. Usiskin states, "For judging a proof, clarity is a more important criterion than the amount of detail" (p. 421). He corroborates this by citing Soviet research which states that a capable mathematics student is one who has the ability to find shortcuts in mathematical arguments.

3. The elimination of the least important theorems of which there are six. This would allow an extra 
two to three weeks of class instruction on informal geometry (Usiskin, 1980).

If students are to experience success in learning geometry, teachers must be aware of how students move from one stage to the next. According to Pierre van Hiele, their progress from one level to the next follows rive phases. These are as follows:

Information: Students become acquainted with the work domain.

Guided orientation: Tasks are performed involving different relations of the network that is to be formed.

Explication: Consciousness of the relations occur. Students attempt to express the relations in more technical language.

Free orientation: Completing more complex tasks leading students to more investigation and knowledge of the properties of shapes.

Integration: The summarizing of all knowledge gained about the subject. Students reflect and summarize the newly formed network of relations (Fuys, Geddes, and Tischler, 1988).

The van Hieles asserted that progress from one level to the next is highly dependent on the instruction the student receives. They stated that, "It is possible, however, that certain methods of teaching do not permit the attainment of 
the higher levels, so that methods of thought used at these levels remain inaccessible to the student" (van Hiele, 1984, p. 246).

\section{Manipulatives}

Experience with manipulative materials, regardless of the developmental level of the student, aids in providing a strong foundation for conceptual understanding whether it be counting skills or the understanding of properties and relationships (Moser, 1986). The van Hieles strongly emphasized the use of manipulatives when teaching geometry to help facilitate the transition from one level to the next (Fuys, Geddes, and Tischler, 1988).

Piaget also emphasized the use of manipulatives. Piagetian dictum states that a child's learning involves a process of physically and mentally manipulating and transforming the real world. This manipulation leads to understanding and abstraction (Piaget, 1968). It is only after this process that a child can grasp the symbols attached to abstractions (Suydam and Weaver, 1975).

Kennedy states that general agreement has been reached supporting the use of manipulatives. He further suggests that children, who have a solid foundation in the use of manipulative materials, are more likely to bridge the gap from the concrete to the abstract. Manipulatives perform an important function; that of helping students understand 
mathematical concepts and the ability to apply these concepts to real world situations (Kennedy, 1986).

According to Suydam and Higgins, in almost fifty percent of the studies considered, students who learned by the use of manipulatives scored significantly higher than those who did not get the benefit of this experience. Most of the remaining studies showed that scores were almost the same. There were very few instances of higher achievement by those who were not using manipulative materials (1977). This finding was substantiated by Parham who reported that there was a decided difference between those who used manipulative materials and those who did not. Those using manipulatives scored near the eighty-fifth percentile (Parham, 1983). A study conducted by Canny suggested that retention was higher when using manipulatives than when manipulatives were not in use (Canny, 1984).

There is a question as to whether manipulatives are beneficial above the elementary school level. This was answered by Driscoll, who stated that manipulatives not only have a place at the elementary level, but also in the intermediate grades for remedial help, as well as to teach new concepts (Driscoll, 1988). Driscoll's claim is substantiated by suydam stating that lessons using manipulatives produced greater learning than those that did not. Suydam went on to say that achievement is enhanced at 
every grade level, through a variety of topics and at all ability levels (Suydam, 1984).

Manipulative materials allow for a greater degree of participation in a lesson. This creates greater motivation and interest in mathematics (Hynes, 1986).

The teacher's potential for affecting student motivation, positively or negatively, is awesome. While, in the end, motivation must come from within each student, it can only come when the student feels the excitement of learning, experiences his or her efforts as appreciated, gets some clarity on goals, makes some connection between the work done in mathematics class and those goals, and feels the confidence and freedom to risk attaining them (Driscoll, 1988, p. 63).

The Teacher

Fuys, Geddes, and Tischler, using the van Hiele model as the basis for their study, found that geometry was often a neglected part of the mathematics curriculum and students were usually taught by rote memorization or in a manner which required very little student explanation. The study further pointed out that rote memorization should be avoided for a number of reasons. This approach to teaching prevents students from involving themselves in appropriate thinking about geometry. Students are not learning geometry simply by memorizing geometric relationships without trying to explain the underlying concepts. They tend to forget or confuse what they have memorized. Geometry becomes just rote-memorization, and because of this, students tend not to wonder if properties are true, and if they are true, why 
(Fuys, Geddes, and Tischler, 1988). Yet despite the current research, many teachers still use traditional rote-memorization along with a heavy reliance on the textbook when teaching geometry (Driscoll, 1988).

After twenty years of research, Suydam and osborne found that many teachers use no instructional materials other than the textbook and chalkboard (1977). Of the thirty-two most widely used textbooks, only three were found to be based on research and development. The rest were based on "conventional wisdom" (Suydam and Osborne, 1977). Much of the burden rests on the teacher to deliver the necessary curriculum in an interesting manner (Hynes, 1986). The teacher's role is critical if successful use of manipulatives is to be obtained. According to a recent national survey, most teachers do not use manipulative materials after the primary grades. The report stated that of the kindergarten through sixth grade teachers polled, nearly half reported using manifulatives less than once per week or not at all (Fey, 1979).

Driscoll states that when manipulatives are used in the classroom, teachers take on the role of guides, rather than the traditional role of lecturers. They also insure that there are a variety of manipulative materials available to be used in a variety of ways, allowing students the opportunity to build from the concrete to the abstract level. Because children learn in different ways, this variety of choice is essential (1988). 
According to the Mathematics Framework for California Public Schools Kindergarten Through Grade Twelve, teachers should appropriately balance the right amount of concrete and symbolic models so that thorough understanding of the concepts can be achieved by students. The Framework states that "to be effective, teachers must do more than just provide concrete materials for their demonstrations. students need to interact with the materials directly, continue to use materials as they develop understanding, and refer to the materials as they solve problems" (1985, p. 16). State and National Recommendations

The geometry curriculum has been undergoing some dramatic changes. According to the Mathematics Framework for California Public Schools Kindergarten Through Grade Twelve, students in grades six through eight should be able to understand geometric terms, have the ability to measure and construct lines and angles, and be able to identify twoand three-dimensional figures. They should be able to determine relationships between figures and perform transformations, being able to solve problems using their knowledge of geometry, giving relationships involving geometric elements (1985). These relatively new guidelines are in line with the van Hiele research.

on a national level, the standards listed in the National Curriculum and Evaluation standards, for the most 
part, correspond with the California Mathematics framework and the van Hiele levels. The geometry objectives are as follows:

In grades $k-4$, the mathematics curriculum should include two- and three-dimensional geometry so that students can,

- describe, model, draw, and classify shapes;

- investigate and predict results of combining, subdividing, and changing shapes;

- develop spatial sense;

- relate geometric ideas to number and measurement ideas;

- recognize and appreciate geometry in their world (National Council of Teachers of Mathematics, 1988, p. 7$)$.

The Kindergarten through fourth grade standards correspond to van Hiele level zero. The standards for grades 5-8 correspond to van Hiele levels zero and one (Fuys, Geddes, and Tischler, 1988). These standards are as follows:

- identify, describe, compare, and classify geometric figures;

- visualize and represent geometric figures with special attention to developing spatial sense;

- explore transformations of geometric figures;

- represent and solve problems using geometric models;

- understand and apply geometric properties and relationships; 
- develop an appreciation of geometry as a means of describing the physical world (National Council of Teachers of Mathematics, 1988, p. 11).

The standards are a good start; however, they can hardly prepare students for formal proofs beginning in grade nine. A more in-depth investigation of the soviet model may be worth examining to use as a model for other countries; the United States in particular (Fuys, Geddes, and Tischler, $1988)$

The Soviet Union has taken the van Hiele research and incorporated the model into the soviet curriculum (Fuys, Geddes, and Tischler, 1988). The influence of the van Hiele model has resulted in the study of various physical models of geometric shapes and solids being given a high priority in the pre-secondary s:hool curriculum. Soviet children study the properties of geometric shapes and the relationships among them in the first three grades and they are taught the measurement of geometric magnitudes. Students have completed many of the van Hiele Level one activities by the time they enter the fourth grade. They then begin a semi-deductive study of geometry that continues for the next seven years (Shaugnessy and Burger, 1985).

\section{Summary}

In summation, according to the van Hiele research and other corresponding research, middle and high school students are being presented with geometric concepts that 
are far beyond their cognitive levels. Progression from the concrete level to the abstract may be enhanced by the use of manipulative materials. Manipulatives provide students with hands-on activities which aid in building a solid foundation so that abstract thinking may be achieved. The teacher's role is of paramount importance if manipulatives are to be successfully used in the classroom. The Mathematics Framework for California Public Schools Kindergarten Through Grade Twelve (1985) and the Curriculum and Evaluation Standards for School Mathematics (1989) agree that manipulative materials are necessary in the geometry curriculum. 
CHAPTER III - THE METHODOLOGY

Many students entering high school are choosing not to take courses in geometry. One of the reasons for this is that geometry has been a frustrating experience for them in the earlier grades (Prevost, 1985). Students experience a lack of understanding of even the most basic geometric principles, and get little if any hands-on experience (Fey, 1979). Another problem is that students have been exposed to concepts beyond their cognitive levels. The van Hiele research suggests that students should be given more experiences, at a much younger age, with physical representations of shapes so that they can explore the properties of shapes before going on to proofs and formulas (Fuys, Geddes, and Tischler, 1988). The purpose of this research was to compare two methods of teaching geometry, one using a traditional textbook method and the other using a manipulative method as suggested by the van Hiele research.

Research Universe and Sampling Procedure

The sample population was chosen from 120 advanced sixth grade students at the king Middle school in the Monterey Peninsula Unified School District. Selection was based on attaining achievement scores above the 70 th percentile on the Mathematics section of the California Test of Basic Skills, level 6 . 
Sixty students in all were used for the research. AII sixty students were routinely placed in two separate . advanced classes by school counselors. One class of thirty students was randomly chosen as the control group, and the other was designated the experimental group. Both groups had comparable socio-economic and ethnic backgrounds as well as comparable mathematics grades, according to their cumulative files. Both groups had comparable male/female ratios and were instructed by the same teacher.

\section{Iimitations}

(1) The time of day students have mathematics may be a factor in how well they learn the concept being taught.

(2) Illness or tardiness may be factors affecting the outcome of test results.

(3) Ethnic backgrounds, resulting in some language problems, may affect the posttest results.

Delimitations

(1) The content tested was limited to area, volume, perimeter and angle measurement of various polygons.

(2) California Test of Basic Skills scores were comparable at the beginning of the study.

(3) Grade level was the same for both groups.

(4) Male/Female ratio was comparable. 
Timetable and Method of Delivering Material

Counselors placed students in september of 1988. The study began on March 15, 1989 and ended the first week of May, 1989. Pre- and posttests, consisting of both

teacher-made and textbook tests, were administered. The same teacher-made test was used at the beginning and end of the treatmen. period, whereas the textbook tests were parallel forms.

The teaching methodology for the control group was based on objectives designated by the sixth grade scott-Foresman textbook, Invitation to Mathematics. The objectives covered dealt with properties of circles and polygons, as well as the appropriate angle measurement of various polygons. The students were expected to compute the perimeters and areas of polygons and circles, as well as volume and surface area of given rectangular and triangular prisms. The final objective covered was the construction of parallel lines, perpendicular lines, and equilateral triangles using a compass and straight-edge. Because the class was advanced, the seventh grade Scott-Foresman textbook was used as well as the sixth grade textbook. The teacher-made achievement test covered the extra objectives from the seventh grade text.

The teaching methodology for the experimental group was based on the use of concrete materials such as tangrams, geoboards, and geometrically shaped blocks. The computer 
was also used as a manipulative in this study. The Logo programming language allowed students to construct various shapes and then manipulate them using the keyboard and monitor.

WEEK ONE

CONTROL GROUP - Instruction began with an introduction to geometry, followed by angle measurement and learning how to use a protractor according to the directions given by the textbook. Measurement of triangles took place with students learning that all three angles equal a total of 180 degrees. Angle measurements of different polygons followed. This was accomplished by dividing the polygons into triangles and dividing by the number of angles. Small groups were formed and patterns were found, which led to a mathematical formula. Construction of parallel lines, perpendicular lines and equilateral triangles took place. A compass and straight-edge were used with the control group in accordance with what the textbook suggested.

EXPERIMENTAL GROUP - The experimental group learned to use a protractor, compass and straight-edge, in much the same manner as the control group. The experimental group was given geoboards to construct various polygons, dividing them up into triangles and finding formulas for the interior angles. The experimental group was also given computer lab instruction, creating the various shapes using Apple Logo.

WEEK TWO

CONTROL GROUP - The control group received board instruction and review quizzes for angles. Tesselations were made using rulers only. The group was expected to understand the concept of angles meeting at the vertex at 360 degrees. They were also expected to understand which shapes tesselated and which shapes did not. A quiz was given at the end of the week. 
EXPERIMENTAL GROUP - The same objectives were taught but tesselations were made using geometrically shaped blocks and tangrams. The computer programming language, Logo, was used to construct various shapes by using the appropriate angle measurements. A quiz was given at the end of the week.

\section{WEEK THREE}

CONTROL GROUP - The control group was instructed on how to compute the perimeter and area of triangles and parallelograms as suggested by the textbook. Worksheets which accompanied the textbook were given. The chalkboard was used by the teacher to demonstrate the concepts. They used a ruler, according to textbook instructions, to physically measure shapes provided in the textbook to enable them to compute area and perimeter. Dot paper was used by the group. A quiz was given at the end of the week.

EXPERIMENTAL GROUP - The experimental group used geoboards and tangrams instead of board explanations to learn perimeter and area of triangles and parallelograms. Dot paper was used as the transition between the concrete and abstract. A quiz was given at the end of the week.

\section{WEEK FOUR}

CONTROL GROUP - The area of trapezoids was taught. The control group was instructed using worksheets provided by the textbook. Students were formed into groups solving problems provided by the textbook. Area and circumference of circles was discussed using the method described by the textbook. A quiz was given at the end of the week.

EXPERIMENTAL GROUP - The experimental group used geoboards, Pattern Blocks, and tangrams to discover the area of trapezoids. Construction paper and rulers were used, in a group situation, to discover the area and circumference of circles. Logo was also used at the end of the week for quiz purposes. 


\section{WEEK FIVE}

CONTROI GROUP - The lesson began with a discussion of three-dimensional objects. Students made charts of vertices, edges, and faces of prisms and pyramids. A pattern was found. The textbook was used for this lesson along with the worksheets provided. The control group visualized the objects as diagrammed in the textbook or on the chalkboard. The surface area of triangular and rectangular prisms and pyramids was taught. Diagrams from the textbook were presented. Chalkboard diagrams and drawings were used, as well as looking at shapes around the classroom.

EXPERIMENTAI GROUP - Students made charts of three-dimensional objects much as the control group except that the experimental group was provided with pyramid and prism shaped blocks. This group handled the objects as much as necessary to finish the assigiument. The pyramid and prism shaped blocks were also used to teach surface area. The experimental group took apart shoe boxes and physically measured the area of each side, computed the sum, and obtained the surface area.

\section{WEEK SIX}

CONTROI GROUP - VOlume was discussed. The control group used the textbook and accompanying worksheet activities. On Thursday of the sixth week, a total review of the concepts taught in the last six weeks took place. The group reviewed by using worksheets which were completed in small groups.

EXPERIMENTAL GROUP - Volume was taught using a rectangular solid with centimeter cubes to aid in the understanding of the concept. The centimeter cubes were used to fill up the rectangular solid. The students were then instructed to compute the sum of the centimeter cubes and thus obtain volume. A total review took place on Thursday of this week. Tangrams, geoboards, geometrically shaped blocks, and Logo was used in a small group situation.

\section{WEEK SEVEN}

CONTROL AND EXPERIMENTAL GROUPS - BOth groups continued with the overall review. On April 30 , 1989, posttesting began. The textbook 
examination was given first, followed by the teacher-made examination.

\section{Data-gathering Tools/Instruments}

Data were gathered from pre- and posttest scores, from the teacher's roll sheets (for the purpose of detemining who was absent and who was not), and from the student cumulative files to determine ethnic background possibly resulting in language barriers. Procedures for Collection of Data

Ninety minutes were allotted for each group to complete both tests. Tests were collected and scored by the instructing teacher. The pre- and posttests were then independently scored by another teacher to insure accuracy. The results for both teachers were the same. The location of the pre- and posttests was the same for both groups. The groups were tested at different times of the day because of the different class schedules, although both groups were tested in the morning. Procedures for Analysis of Data

The raw scores were summarized using a statistical program for the Macintosh computer which calculated means, medians, modes, standard deviations, and variances. The raw data were entered into the computer by a hired data entry clerk. Independent samples t-tests were used to compare experimental and treatment group mean scores on the pre- and postests. 


\section{CHAPTER IV - RESULTS}

Statistical analyses described in this section were performed to evaluate two methods of teaching geometry, the textbook method and the manipulative method. Independent samples t-tests were used to compare both pre- and posttest scores between the experimental and control grcups. Tables 1 through 4 contain the statistical results for this study. Out of the original 60 students, 44 remained in the study throughout the entire seven week period. Seven students had schedule changes, six students had excessive absences (over five days), and three stucents had been incorrectly placed in the advanced class (their California Test of Basic Skills scores being below the 70th percentile).

Table 1 shows raw scores for the control group, indicating the number of students, means, standard deviations, and variances of the textbook pre- and posttest, as well as the teacher-made pre- and posttest. Table 2 provides the same information for the experimental group.

Table 3 illustrates the results for a t-test comparing pretest means for the control and experimental groups. Using the following formula taken from Best and Kahn (1986), 


$$
t=\frac{\bar{x}_{1}-\bar{x}_{2}}{\sqrt{\frac{\left(N_{1}-1\right) S_{1}^{2}+\left(N_{2}-1\right) S_{2}}{N_{1}+N_{2}-2}\left(\frac{1}{N_{1}}+\frac{1}{N_{2}}\right)}}
$$

no statistically significant differences were found between the textbook pretest scores for the control and experimental groups. The $t$ of .506 does not exceed either 2.021 for a two-tailed test at the .05 level or 2.704 for $a$ two-tailed test at the .01 level, indicating no statistically significant difference on the textbook pretest. For the teacher-made test, the $t$ of 1.08 does not exceed the critical values just cited for a two-tailed test at either the .05 level or the .01 level, and so no significant differences existed between the control and experimental groups on either test at the beginning of the study.

Table 4 shows means, standard deviations, and t-test results for the control and experimental groups after treatment. Again, applying a t-test for independent samples, a $t$ of 3.33 with 42 degrees of freedom is statistically significant at the .01 level. Therefore, it can be concluded that the group using the textbook method had a significantly lower mean achievement score than did the manipulative method group. Similarly for the teacher-made test, the $t$ of 5.69 exceeds the critical value of 2.704 for a two-tailed test at the .01 level with 42 degrees of freedom. There was a statistically significant 
Table 1

Pretest and Posttest Scores for Control Group

Indicating Number of Students, Total Points

Possible, Means, and Standard Deviations

\begin{tabular}{lcccc}
\hline & \multicolumn{2}{c}{ Textbook Test } & \multicolumn{2}{c}{ Teacher-Made Test } \\
& Pretest & Posttest & Pretest & Posttest \\
\hline$\underline{N}$ (\# of students) & 22 & 22 & 22 & 22 \\
Total Possible & 26 & 26 & 25 & 25 \\
Mean & 3.16 & 18.09 & 0.89 & 15.27 \\
Standard Deviation & 2.50 & 4.37 & 1.60 & 5.46 \\
\hline
\end{tabular}

Table 2

Pretest and Posttest Scores for Experimental Group Indicating Number of Students, Total Possible Points, Means, and Standard Deviations

\begin{tabular}{lcccc}
\hline & \multicolumn{2}{c}{ Textbook Test } & \multicolumn{2}{c}{ Teacher-Made Test } \\
& Pretest & Posttest & Pretest & Posttest \\
\hline N (\# of students) & 22 & 22 & 22 & 22 \\
Total Possible & 26 & 26 & 25 & 25 \\
Mean & 2.77 & 21.77 & 1.45 & 18.91 \\
Standard Deviation & 2.62 & 2.79 & 1.84 & 3.55 \\
\hline
\end{tabular}


Table 3

Comparison of Pretest Means and Standard Deviations for Control and Experimental Groups

\begin{tabular}{lcccc}
\hline & Experimental & Control & df & $t$ \\
\hline $\begin{array}{l}\text { Mean for textbook test } \\
\text { standard deviation }\end{array}$ & 2.77 & 3.16 & & \\
$\begin{array}{l}\text { Mean for teacher-made test } \\
\text { standard deviation }\end{array}$ & $(2.62)$ & $(2.50)$ & 42 & $.506+$ \\
& $(1.84)$ & $(1.60)$ & 42 & $1.08+$ \\
\hline
\end{tabular}

+Not significant

Table 4

Comparison of Posttest Means and Standard Deviations for Control and Experimental Groups

Experimental Control df $t$

\begin{tabular}{lllll} 
Mean for textbook test & 21.77 & 18.09 & & \\
standard deviation & $(4.37)$ & $(2.79)$ & 42 & $3.33^{*}$ \\
$\begin{array}{lllll}\text { Mean for teacher-made test } \\
\text { standard deviation }\end{array}$ & $\begin{array}{ll}18.91 \\
(3.55)\end{array}$ & $(5.46)$ & 42 & $5.69 *$ \\
\hline
\end{tabular}

*Significant at the .01 level 
difference between the group using the textbook method and the group using the manipulative method on the teacher-made test in favor of the manipulative method group. In summation, before treatment no statistically significant differences were found on either the textbook or the teacher-made pretests. After treatment, however, statistically significant differences were found between groups on both the textbook and teacher-made posttests in favor of the manipulative method. 
CHAPTER V - SUMMARY, DISCUSSION, RECOMMENDATIONS Summary

This study investigated two methods of teaching geometry, the traditional textbook method and the manipulative method. The study was conducted over a seven week period with sixty students who were placed in either a control or an experimental group. The subjects were pretested on the first day using a textbook and a teacher-made test. They were tested in the same manner again on the last day. It was hypothesized that there would be a significant difference in posttest scores between students who were taught using the manipulative method and those taught by the textbook method.

The curriculum taught and tested included the properties of circles and polygons, as well as the appropriate angle measurements of various polygons. The manipulative materials used were tangrams, Logo, a compass and a straight-edge. The students were also expected to compute the perimeters and areas of polygons and circles. The manipulatives used were the geoboards and dot paper. Pattern Blocks were used to further explore angle measurements and tesselations. They were to determine the volumes and surface areas of given rectangular and triangular prisms. The manipulative materials used were various geometrically shaped blocks consisting of prisms and pyramids. Finally, the students were tested on the 
construction of parallel and perpendicular lines, and constructing equilateral triangles using a compass and straight-edge. Manipulative materials were used with the experimental group, while the control group was taught using the traditional textbook method.

Sixteen students out of the original sixty were eliminated from the experiment because of illness, schedule changes or because their CTBS scores were lower than the 70 th percentile. This left twenty-two in each group.

\section{Discussion}

The control and experimental groups were shown to be at approximately the same level before treatment as indicated by both the textbook and teacher-made pretests. Independent $t$-tests were used to compare both pre- and posttest scores between the control and experimental groups. The $t$-score for the textbook pretest was .506 , and the $t$ score for the teacher-made pretest was 1.08 , both not exceeding the $t$ critical value of 2.021 for a two-tailed test at the .05 level at 42 degrees of freedom.

After treatment, the experimental group, those students using the manipulative method, showed significant improvement over the control group, those students using the textbook method, on both the textbook and teacher-made posttest. The t-scores were 3.33 on the textbook posttest and 5.59 on the teacher-made posttest, both scores exceeded the $t$ critical value of 2.704 for a two-tailed test at the 
.01 level with 42 degrees of freedom. The data suggests that the manipulative method was more effective than the textbook method.

The experiment was born out of the var Hiele research which indicated that geometry was being taught above the cognitive level of middle school students. The research was conducted to find out whether or not this theory proved to be valid. This research project substantiated the van Hiele's theory which stated that students were not cognitively ready, at the middle school level, to handle the abstract approach of the textbook, and that they needed to use concrete materials to gain a visual representation of the concepts being taught. Manipulative materials, according to the van Hieles, provide the student a bridge between the concrete and the abstract. Recommendations

The manipulative materials used in this study included geoboards, tangrams, Pattern Blocks, and the computer. Depending on the topic being taught, it is recommended that a greater variety of manipulative materials be used at the middle school level or even earlier to enable students to build a strong foundation for later abstract work in geometry .

The Soviet Union has taken the van Hiele research and practically applied it in thej.x schools. It is recommended that this research be applied to geometry courses in this country. 
References

Beaulieu, Roderic A. Patterns of Verbal Behavior in Secondary School Geometry Classes, (Doctoral

dissertation, Columbia University Teachers College, 1979). Dissertation Abstracts International, 39A, 7202.

Best, John W. \& James V. Kahn. (1986). Research in Education, Prentice-Hall, Cliffs, N.J.

Brown, John K., Jr. Textbook use by Teachers and Students of Geometry and second Year Algebra, (Doctoral dissertation, University of Illinois at Urbana-Champaign, 1973). Dissertation Abstracts International, 34A, 5795-5796.

California State Department of Education. (1985). Mathematics Framework: For California Public schools Kindergarten Through Grade Twelve, Sacramento, CA.

Canny, Marie E. The Relationship of Manipulative Materials to Achievement in Three Areas of Fourth-Grade Mathematics: Computation, Concept Development and Problem Solving, Dissertation Abstracts International, 45A, 775-776.

Cox, Philip L. (1985). Informal Geometry - More is Needed, Mathematics Teacher, 78, 404-405.

Driscoll, Mark J. (1988). Research Within Reach: Elementary School Mathematics, National Council of Teachers of Mathematics, Reston, VA.

Driscoll, Mark J. (1988). Research Within Reach: Secondary School Mathematics, National Council of Teachers of Mathematics, Reston, VA.

Fey, James T. (ed.). (1984) . Computing and Mathematics: The Impact on Secondary school Curriculum, National council of Teachers of Mathematics, Reston, VA.

Fuys, D., Geddes, D. , \& Tischler, R. (1988). The van Hiele Model of Thinking in Geometry Among Adolescents, Journal For Research in Mathematics Education, National Council of Teachers of Mathematics, Reston, VA.

Gardner, Martin. (1982). Aha! Gotcha: Paradoxes to Puzzle and Delight, W.H. Freeman and Company, Niw York.

Heddens, James $W$. (1986). Bridging the Gap between the Concrete and the Abstract, Arithmetic Teacher, 3 , 14-17. 
Herbert, Elizabetr. (1985). Manipulatives are Good Mathematics, Arithmetic Teacher, $\underline{32}, 4$.

Hoffman, Nathan. Geometry in Mathematics: A Survey of Some Recent Proposals for the Content of Secondary School Geometry, (Doctoral aissertation, University of Montana, 1973). Dissertation Abstracts International, 34A, 3026 .

Hynes, Michael c. (1986). Selection Criteria, Arithmetic Teacher, $3,11-13$.

Kennedy, Leonard M. (1986). A Rationale, Arithmetic Teacher, $3,6-7$.

Moser, James M. (1986). Curricular Issues, Arithmetic Teacher, $3,8-10$.

National Council of Teachers of Mathematics. (1988). The Curriculum and Evaluation Standards for School Mathematics, Reston, VA.

O'Daffer, Phares G., \& Clemens, Stanley R. (1977). Geometry: An Investigative Approach, Addison-Wesley Publishing Co., Menlo Park, CA.

Parham, Jaynie L. A Meta-Analysis of the Use of Manipulative Materials and Student Achievement in Elementary School Mathematics, Dissertation Abstracts International, 44A $(1983), 96$.

Pedoe, Dan. (1983). Geometry and the Visual Arts, Dover Publications, Mineola, N.Y.

Peterson, John C. (1973). Informal Geometry in Grades 7-14, Geometry in the Mathematics Curriculum, Thirty-Sixth NCTM Yearbook, National Council of Teachers of Mathematics, Reston, VA.

Piaget, Jean. (1968). Six Psychological Studies, Random House, Inc., New York.

Prevost, Ferdinand J. (1985). Geometry in the Junior High School, Mathematics Teacher, 78, 411-418.

Shaughnessy, Michael J. \& Burger, William F. (1985). Spadework Prior to Deduction in Geometry, Mathematics Teacher, 78, 419-427. 
Suydam, Marilyn N. (1985). The Shape of Instruction in Geometry: Sone Highiights from Research, Mathematics Teacher, 78, 481-486.

Suydam, Marilyn N., \& Higgins, John I. (1977). ActivityBased Learning in Elementary School Mathematics: Recommendations from Research, National Council of Teachers of Mathematics, Reston, VA.

Suydam, Marilyn N. , \& Osborne Alan. (1977). The Status of Pre-College Science, Mathematics, and Social Science Education: 1955-1975 volume II: Mathematics Education, The Ohio State University Center for Science and Mathematics Education, Columbus, $\mathrm{OH}$.

Suydam, Marilyn N., \& Weaver, Fred J. (1975). Research on Mathematics Learning. Mathematics Learning in Early Childhood. 37th NCTM Yearbook, Reston, VA., National Council of Teachers of Mathematics.

Usiskin, zalman. (1980). What should Not Be in the Algebra and Geometry Curriculum of Average College Bound Students?, Mathematics Teacher, 73, 413-24. 